Research Article

\title{
Study of Craniometric Point as a Landmark in Performing Posterolateral Surgeries on Skull
}

\author{
Sachin Patil', Dharmendra Kumar
}

${ }^{1}$ Assistant Professor, Department of Anatomy, ANIIMS, Port Blair, Andaman and Nicobar Islands, India.

${ }^{2}$ Associate Professor \& Head, Department of Physical Medicine and Rehabilitation, ANIIMS, Port Blair, Andaman and Nicobar Islands, India.

DOI: https://doi.org/10.24321/2454.8642.201917

\section{I $\quad \mathbf{N} \quad \mathbf{F} \quad \mathbf{O}$}

\section{Corresponding Author:}

Dharmendra Kumar, Department of Anatomy, ANIIMS, Port Blair, Andaman and Nicobar Islands, India.

E-mail Id:

dharmendra744101@gmail.com

Orcid Id:

https://orcid.org/0000-0001-9722-5107

How to cite this article:

Patil S, Kumar D. Study of Craniometric Point as a Landmark in Performing Posterolateral Surgeries on Skull. Rec Adv Path Lab Med 2019; 5(3): 17-19.

Date of Submission: 2019-07-15

Date of Acceptance: 2019-09-16

\section{$\begin{array}{llllllll}\mathbf{A} & \mathbf{B} & \mathbf{S} & \mathbf{T} & \mathbf{R} & \mathbf{A} & \mathbf{C} & \mathbf{T}\end{array}$}

Introduction: The asterion is craniometric point on the lateral side of skull. Importance of asterion lies in that it is primary landmark in performing posterolateral surgeries on skull.

Material and Methods: In 100 adult dry skulls measurements were taken on right and left sides of the skull using digital Vernier callipers. Two parameters were noted: Distance of the asterion to the root of zygoma and to the tip of the mastoid process.

Result: The mean distance of the asterion to the root of zygoma on right side was $56.15+2.40 \mathrm{~mm}$ and on left side was $57.48+2.68 \mathrm{~mm}$. The mean distance of the asterion to the tip of the mastoid process on the right side was $48.77+2.23 \mathrm{~mm}$ and on the left side was $47.45+2.62 \mathrm{~mm}$.

Conclusion: The accurate location of asterion using the root of the zygoma and the tip of the mastoid process needs to be further evaluated using more sophisticated studies.

Keywords: Anatomy, Asterion, Sigmoid Sinus, Surgical Approach

\section{Introduction}

The asterion is craniometric point , an anatomical structure used as a point of origin in locating other anatomical structures during surgery or as point from which measurements can be taken on the lateral side of skull. It is the junction of the lambdoid, occipitomastoid and parietomastoid sutures. ${ }^{1}$ Importance of asterion lies in that it is primary landmark in performing posterolateral surgeries on skull. But the location of asterion is so variable that, purely depending on it can be a difficult issue. ${ }^{2}$ Therefore, this study was conducted to determine the usefulness of the asterion as a surgical landmark for posterolateral surgeries in posterior cranial fossa on skull. For performing the initial burr hole for retro sigmoid craniotomy, the surgeon to know the site of exact location of burr hole. ${ }^{3}$ The sigmoid sinus is easily damaged during posterior fossa craniotomy because it is seated ingroove in the bone and connected by an emissary vein. Variations in location of the asterion and its distance from the root of the zygomatic process and mastoid tip are some important parameters useful during surgeries in this region. ${ }^{4,5}$

This study aimed at determining the anatomic situation of asterion in an Indian population using distance from the root of the zygoma and the tip of the mastoid process as reference points.

\section{Material and Methods}

Hundred adult dry skulls of unknown sex and age were used for this study. The dry skulls were obtained from the bone bank of our medical college. Those that had the $3^{\text {rd }}$ molar 
erupted were considered adults and were hence studied. Any skull with gross pathology or abnormality or damage were excluded from study. Measurements were taken on right and left sides of the skull using digital Vernier callipers. Two parameters were noted 1) Distance of the asterion to the root of zygoma 2) Distance of the asterion to the tip of the mastoid process (Figure 1). Each of the measurements were taken thrice then averaged so as to minimize bias.

\section{Statistical Analysis}

Data obtained were analysed using SPSS 17 software. The t-test was applied in the assessment of side and differences. P-value $<0.05$ was considered significant.

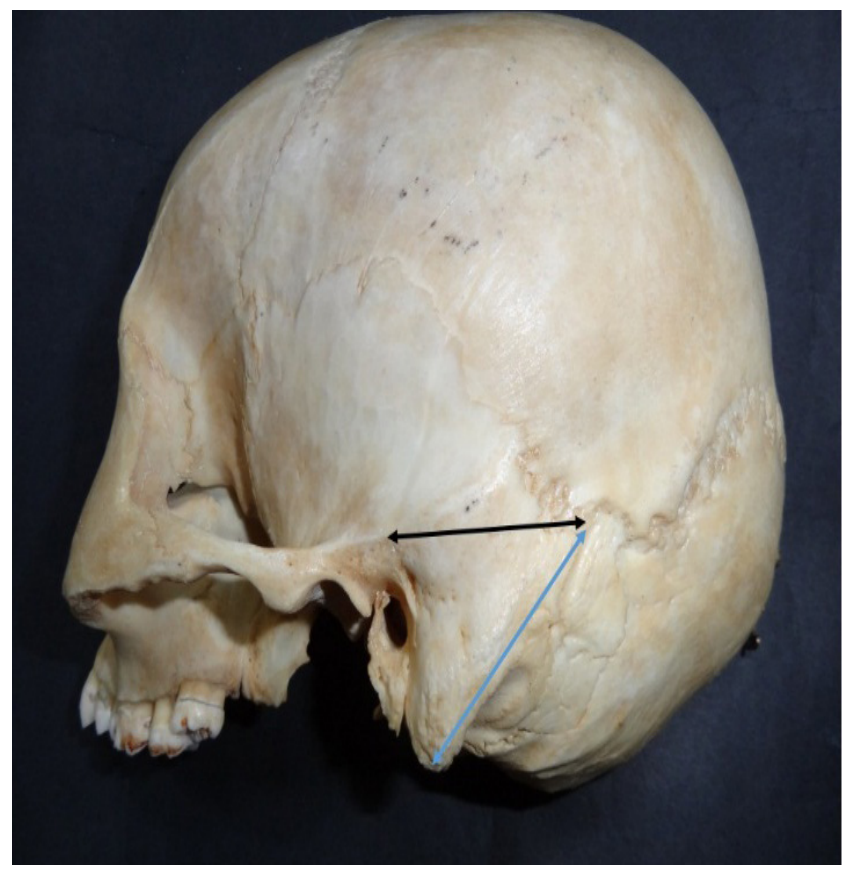

Figure I.Measurement of distance of the asterion to the root of zygoma (black line) and to the tip of the mastoid process (blue line)

\section{Result}

Table 1, shows the means and standard deviations of the two measurements of distance of the asterion to the root of zygoma and distance of the asterion to the tip of the mastoid process on the right and left sides. No statistically significant side differences were found in the location of the asterion from the root of the zygoma as well as from the tip of the mastoid process. The mean distance of the asterion to the root of zygoma on right side was $56.15 \pm 2.40$ $\mathrm{mm}$ while the mean distance of the asterion to the root of zygoma on left side was $57.48 \pm 2.68 \mathrm{~mm}$. The mean distance of the asterion to the tip of the mastoid process on the right side was $48.77 \pm 2.23 \mathrm{~mm}$ and mean distance of the asterion to the tip of the mastoid process on the left side was $47.45 \pm 2.62 \mathrm{~mm}$.
Table I.Position of the asterion from the root of the zygoma and the tip of mastoid process

\begin{tabular}{|c|c|c|c|}
\hline Parameter & Right & Left & P-value \\
\hline $\begin{array}{c}\text { Distance of the } \\
\text { asterion to the } \\
\text { root of zygoma }\end{array}$ & $\begin{array}{c}56.15 \pm 2.40 \\
(\mathrm{~mm})\end{array}$ & $\begin{array}{c}57.48 \pm 2.68 \\
(\mathrm{~mm})\end{array}$ & 0.062 \\
\hline $\begin{array}{c}\text { Distance of } \\
\text { the asterion to } \\
\text { the tip of the } \\
\text { mastoid process }\end{array}$ & $\begin{array}{c}48.77 \pm 2.23 \\
(\mathrm{~mm})\end{array}$ & $\begin{array}{c}47.45 \pm 2.62 \\
(\mathrm{~mm})\end{array}$ & 0.058 \\
\hline
\end{tabular}

\section{Discussion}

The most important fact in the success of surgery is strategy and planning which is mainly dependent on the surgeon's knowledge of the topographical anatomy of that region. Starting the craniotomy at the right place is the single most factor determining the further success of procedure. ${ }^{6,7}$ This will help in avoiding unnecessary serious complications such as bleeding from laceration to sigmoid or transverse sinus. ${ }^{8}$ This study was targeted at providing information about the anatomical location of asterion for lateral approaches to the posterior cranial fossa which have been widely used in neurosurgeries.

The asterion has been considered as landmark for posterolateral cranial surgeries. The study by Gharabaghi A et al. states that the asterion was located over the posterior fossa in $32 \%$ on the right and $25 \%$ on the left. ${ }^{9}$ This study also states that the transverse-sigmoid sinus junction was on asterion in $61 \%$ of cases on the right and $66 \%$ on the left, while it was located inferiorly in $9 \%$ on the left and in $7 \%$ on the right. ${ }^{10}$ Another study by Tubbs RS et al. found that in $74.4 \%$ the asterion was located superficial to the transverse-sigmoid sinus junction on the right side. ${ }^{11} \mathrm{~A}$ burr hole inferior to superior nuchal line is an alternative route to avoid both the transverse and sigmoid sinuses. ${ }^{12}$ The asterion is not a reliable point for posterolateral route and a burr hole $2 \mathrm{~cm}$ below the asterion is better alternative according to Urculo $\mathrm{E}$ et al. ${ }^{13}$ The relationship of sigmoid sinus with asterion will depend type of mastoid process in relation to pneumatisation as per Mwachaka PM et al. ${ }^{14}$

\section{Conclusion}

The asterion is a useful surface landmark in terms of locating the site for initial burr hole over the posterior fossa. As for the present study, distance of asterion from root of zygoma and tip of mastoid can be used for location of this surgical landmark. The imaging techniques like CT are capable of accurately visualizing the bony landmark and underlying the Dural sinus. The accurate location of asterion using the root of the zygoma and the tip of the mastoid process needs to be further evaluated using more sophisticated studies. 


\section{Acknowledgement: None}

Conflict of Interest: None

\section{References}

1. Daj DT, Tschabitscher M. Anatomic position of the asterion. Neurosurg 1998; 42(1): 198-199.

2. Day DJ, Kellogg JX, Tschabitscher M et al. Surface and superficial surgical anatomy of the posterolateral cranial base: significance for surgical planning and approach. Neurosurg 1996; 38(6): 1079-1084.

3. Lang J, Samii A. Retrosigmoidal approach to the posterior cranial fossa. Acta Neurochir 1991; 111: 147-153.

4. Tedeshi T, Rhoton AL. Lateral approaches to the petroclival region. Surg Neurol 1994; 41: 180-216.

5. Rhoton AL. Surface and superficial surgical anatomy of the posterolateral cranial base: significance for surgical planning and approach. Neurosurg 1996; 38(6): 1079-108.

6. Ahlhelm F, Nabhan A, Naumann N, et al. Skull base tumors. Radiologe 2005; 45(9): 807-815.

7. Bozbuga M, Boran BO, Sahinoglu K. Surface anatomy of the posterolateral cranium regarding the localization of the initial burr-hole for a retro sigmoid approach. Neurosurg Rev 2006; 29(1): 61-63.

8. Da Silva EB Jr, Leal AG, Milano JB et al. Image-guided surgical planning using anatomical landmarks in the retrosigmoid approach. Acta Neurochir (Wien) 2010; 152(5): 905-910.

9. Gharabaghi A, Rosahl SK, Feigl GC et al. Image-guided lateral suboccipital approach: Part 1-individualized landmarks for surgical planning. Neurosurgery 2008; 62(3) Suppl 1: 18-22.

10. Sheng B, Lv F, Xiao Z et al. Anatomical relationship between cranial surface landmarks and venous sinus in posterior cranial fossa using CT angiography. Surg Radiol Anat 2012; 34(8): 701-708.

11. Tubbs RS, Loukas M, Shoja MM et al. Surface landmarks for the junction between the transverse and sigmoid sinuses: Application of the "strategic" burr hole for suboccipital craniotomy. Neurosurgery 2009; 65 Suppl 6: 37-41.

12. Ucerler H, Govsa F. Asterion as a surgical landmark for lateral cranial base approaches. J Craniomaxillofac Surg 2006; 34(7): 415-420.

13. Urculo $E$, Alfaro $R$, Arrazola $M$ et al. Anatomical landmarks and surgical limits in the suboccipital transmeatal approach to the acoustic neuroma. Neurocirugia (Astur) 2003; 14(2): 107-115.

14. Mwachaka PM, Hassanali J, Odula PO. Anatomic position of the asterion in Kenyans for posterolateral surgical approaches to cranial cavity. Clin Anat 2010; 23(1): 30-33. 